\title{
BIOAKTIVITAS EMPAT SPESIES TUMBUHAN DARI FAMILI EUPHORBIACEAE DAN VERBENACEAE DI HUTAN HUJAN TROPIS KALIMANTAN TIMUR
}

\author{
Wisnu Cahyo Prabowo, Risna Agustina, M. Arifuddin \\ Laboratorium Riset \& Pengembangan Farmaka Tropis, \\ Fakultas Farmasi, Universitas Mulawarman, Samarinda \\ Email:louwishnu@yahoo.com
}

\begin{abstract}
Background and Objectives: The use of biopesticides derived from plants and microorganisms have evolved to replace chemical pesticides that could damage the balance of the ecosystem. The purpose of this study was to screen the bioactivity of larvicides and antimakan plants from Family Euphorbiacea and Verbenacea as basic research and development of biopesticides. Methods: Fresh samples were sorted, cleaned, dried and grinded to obtain simplicia dry powder. Crude drugs were extracted by maceration using methanol for $2 \times 24$ hours. Larvicides bioactivity of the extract was tested against larvae BSLT Artemia Salina Leach and larvae Culex fatigans, while the bioactivity of antimakan tested against the larvae of Tenebrio molitor. Results: Based on this research, it is known that the leaf extract of Lantana camara of Family Verbenacea good activity LC50 against Artemia Salina Leach is 21.65 ppm. Bioactivity of larvicides against Culex fatigans not shown satisfactory results in all extracts tested. best concentration present in the extract Duranta erecta L. of Family Verbenacea with LC95 value of 1,717 ppm. Test results antimakan against Tenebrio molitor has shown good activity in extracts of Euphorbia milli stems from the Family Euphorbiaceae with IC 95 of $2.707 \%$.
\end{abstract}

Keywords : Larvicides, antifeedant, Euphorbiaceae, Verbenaceae, Tropical Rain Forest

\begin{abstract}
ABSTRAK
Latar Belakang dan Tujuan: Penggunaan biopestisida yang berasal dari tumbuhan dan mikroorganisme telah berkembang untuk menggantikan pestisida kimia yang dapat merusak keseimbangan ekosistem. Tujuan penelitian ini adalah untuk menskrining bioaktivitas larvasida dan antimakan tumbuhan dari Famili Euphorbiacea dan Verbenacea sebagai penelitian dasar pengembangan biopestisida. Metode: Sampel segar disortasi, dibersihkan, dikeringkan dan dihaluskan hingga diperoleh serbuk simplisia kering. Serbuk simplisia diekstraksi dengan maserasi menggunakan metanol selama 2 x 24 jam. Bioaktivitas larvasida ekstrak diuji terhadap larva Artemia Salina Leach dan larva Culex fatigans, sedangkan bioaktivitas antimakan diuji terhadap larva Tenebrio molitor. Hasil: Berdasarkan hasil penelitian, diketahui bahwa ekstrak daun Lantana camara dari famili Verbenacea memiliki aktivitas LC $_{50}$ yang baik terhadap Artemia Salina Leach yaitu 21,65 ppm. Bioaktivitas larvasida terhadap Culex fatigans tidak menunjukkan hasil yang memuaskan pada seluruh ekstrak yang diuji. konsentrasi terbaik terdapat pada ekstrak Duranta erecta L. dari Famili Verbenacea dengan nilai LC S5 $_{95}$ sebesar 1.717 ppm. Hasil uji antimakan terhadap Tenebrio molitor memiliki aktivitas yang baik ditunjukkan pada ekstrak batang Euphorbia mili dari Famili Euphorbiaceae dengan $\mathrm{IC}_{95}$ sebesar 2,707 \%.
\end{abstract}


Kata Kunci: Larvasida, Antimakan, Euphorbiaceae, Verbenaceae, Hutan Hujan Tropis

\section{PENDAHULUAN}

Pestisida kimia yang digunakan untuk mengontrol hama diketahui dapat menyebabkan kerusakan lingkungan serta menyebabkan berbagai resistensi pestisida. Penggunaan pestisida kimia dalam kurun waktu panjang juga dapat merusak keseimbangan ekosistem dengan munculnya hama dan wabah yang lebih besar. Karena alasan ini, pencarian metode pengendalian alternatif berupa biopestisida yang berasal dari tumbuhan dan mikroorganisme telah berkembang. Biopestisida mempunyai keuntungan lebih dari pada pestisida kimia, yaitu lebih efektif, aman, dan dapat diterima dilingkungan. Biopestisida sangat baik dalam hal pengembangan dan pengelolaan lingkungan secara terpadu yang ramah dan aman, dengan teknik pendekatan yang kompatibel untuk pengelolaan hama. (Mariadhas, 2013).

Dilaporkan terdapat beberapa penelitian biopestisida tumbuhan dari Famili Euphorbiacea dan Verbenacea dengan hasil yang baik. Aktivitas insektisida beberapa tumbuhan dari Famili Euphorbiace menunjukkan kematian dari Tribolium castaneum pada konsentrasi 5-20\% yang signifikan (Ghulam, 2013). Vitex trifolia, Vitex peduncularis dan Vitex altissima merupakan spesies dari Familly Verbenaceae yang mempunyai aktivitas pada larva Culex quinquefasciatus instar IV sebesar <130 ppm (Kannaathsan K, 2007). Bahkan Ekstrak Petroleum eter daun Vitex negundo dilaporkan memiliki aktivitas larvasida Culex tritaeniorhynchus dengan nilai $\mathrm{LC}_{50} 2,4883 \mathrm{ppm}$ dan $\mathrm{LC}_{90} 5,1883 \mathrm{ppm}$. (Karunamoorthi, 2008).

Skrining tumbuhan sebagai biopestisida dari dua Famili tersebut sangat potensial, terlebih lagi melihat keanekaragaman spesiesnya di hutan hujan tropis Kalimantan Timur.

\section{METODE PENELITIAN}

\section{Koleksi dan Ekstraksi Tumbuhan.}

Tumbuhan diperoleh dari hutan hujan tropis di wilayah kota Samarinda dan sekitarnya pada bulan Februari 2015. Spesies tumbuhan yang dilakukan pengujian antara lain dari Familly Euphorbiaceae (daun Aleuritus moluccana, daun Macaranga gigantean, batang Tinospora crispa dan batang Euphorbia milli) dan Familly Verbenaceae (daun Paronema Canescens, daun Duranta erecta L, daun Callicarpa longifolia L. dan daun Lantana camara). Sampel segar melewati tahap sortasi, pencucian, pengeringan dan penggilingan hingga diperoleh serbuk simplisia kering. Simplisia kering diekstraksi denga maserasi menggunakan metanol selama 2 x 24 jam. Filtrat dipekatkan dan diuapkan sehingga diperoleh ekstrak yang kering.

\section{Uji BSLT (Brine Shrimp Lethality Test).}

Larva naupli Artemia salina $L$ sebanyak 10 ekor dimasukkan ke dalam masingmasing vial yang berisi $5 \mathrm{~mL}$ ekstrak dengan konsentrasi berbeda-beda. Ke dalam vial-vial tersebut dimasukkan 1 tetes larutan ragi $(3 \mathrm{mg} / 5 \mathrm{~mL}$ air laut) sebagai pakan. Vial-vial uji kemudian disimpan di tempat yang cukup mendapat sinar lampu, setelah 24 jam diamati jumlah larva udang yang mati pada masing-masing vial.

\section{Uji Larvasida.}

Telur nyamuk Culex fatigans ditetaskan selama 6-7 hari sampai menetas dan membentuk instar 3 yang akan digunakan sebagai bioindikator. Larva diseleksi yang berukuran kecil dan bentuk fisik yang seragam, kemudian 20 ekor larva dimasukkan ke dalam masing-masing vial yang berisi $50 \mathrm{~mL}$ air. Setiap vial diberikan ekstrak dengan 
konsentrasi berbeda disertai replikasi sebanyak 3 kali. Larva diinkubasi selama 24 jam dan diamati jumlah kematian larva disetiap vial.

\section{Uji Antimakan.}

Daun sawi segar dipotong dengan ukuran $4 \times 4 \mathrm{~cm}$. Daun direndam dengan ekstrak dengan konsentrasi yang berbeda. Kemudian dimasukkan kedalam cawan petri dan ditambahkan ulat Tenebrio molitor sebanyak 10 ekor. Diinkubasi selama 24 jam dan dihitung aktivitas antimakan dengan mengukur luas penghambatan pada daun sawi.

\section{Analisis data.}

Data hasil pengujian toksisitas pada metode BSLT dan pengujian Letal Larvasida berupa persentase kematian larva, sedangkan aktivitas antimakan berupa luas persentase penghambatan menggunakan image ${ }^{\circledR}$. Ketiga hasil tersebut dianalisis menggunakan GraphPad Prisma ${ }^{\circledR}$ sehingga secara berturut-turut diperoleh nilai $\mathrm{LC}_{50}, \mathrm{LC}_{95}$ dan $\mathrm{IC}_{95}$.

\section{HASIL DAN PEMBAHASAN}

Pendekatan uji bioaktivitas yang dilakukan pada penelitian ini dimulai dengan melihat aktivitas terhadap larva udang (Artemia Salina Leach), larva nyamuk (Culex fatigans) dan larva ulat Tenebrio malitor. Pengujian ini mengintrepertasikan aktivitas ekstrak tumbuhan pada 4 spesies dari 2 famili yang berbeda sebagai ukuran kekuatan daya hambat, daya bunuh (letal) dan antimakan pada larva yang merupakan bentuk awal dari organisme hama. Keseluruhan hasil bioaktivitas disajikan pada tabel 1.

Tabel 1. Hasil Bioaktivitas beberapa spesies tumbuhan famili Euphorbiaceae dan Verbenaceae di hutan hujan tropis kalimantan timur

\begin{tabular}{lllll}
\hline & Sampel & LC $_{\mathbf{5 0}}$ BSLT & \multicolumn{1}{c}{$\begin{array}{c}\text { LC95 } \\
\text { Larvasida }\end{array}$} & $\begin{array}{c}\text { IC95 } \\
\text { Antimakan }\end{array}$ \\
\hline & $\begin{array}{l}\text { Ekstrak daun Aleuritus } \\
\text { moluccana }\end{array}$ & $5.231 \mathrm{ppm}$ & $3.029 \mathrm{ppm}$ & $4,787 \%$ \\
$\begin{array}{l}\text { Ekstrak daun Macaranga } \\
\text { Figantea }\end{array}$ & $1.549 \mathrm{ppm}$ & $4.447 \mathrm{ppm}$ & $83,46 \%$ \\
Euphorbiaceae & $\begin{array}{l}\text { Ekstrak batang } \\
\text { Tinospora crispa }\end{array}$ & $211 \mathrm{ppm}$ & $5.538 \mathrm{ppm}$ & $8,414 \%$ \\
$\begin{array}{l}\text { Ekstrak } \\
\text { Euphorbia milli }\end{array}$ & batang & $478,8 \mathrm{ppm}$ & $7.000 \mathrm{ppm}$ & $2,707 \% *$ \\
\hline Rata-rata aktifitas & $1.867,45 \mathrm{ppm}$ & $5.003,5 \mathrm{ppm}$ & $24,84 \%$ \\
\hline $\begin{array}{l}\text { Ekstrak daun Paronema } \\
\text { canescens }\end{array}$ & $215 \mathrm{ppm}$ & $6.731 \mathrm{ppm}$ & $7,564 \%$ \\
$\begin{array}{l}\text { Ekstrak Duranta erecta } \\
\text { Lerbenaceae }\end{array}$ & $269,4 \mathrm{ppm}$ & $1.717 \mathrm{ppm} *$ & $6,645 \%$ \\
$\begin{array}{l}\text { Ekstrak Daun callicarpa } \\
\text { longifolia L. }\end{array}$ & $1.645 \mathrm{ppm}$ & $3.188 \mathrm{ppm}$ & - \\
\hline $\begin{array}{l}\text { Ekstrak Daun Lantana } \\
\text { camara }\end{array}$ & $21,65 \mathrm{ppm} *$ & $1.989 \mathrm{ppm}$ & $15,78 \%$ \\
\hline Rata-rata aktifitas & $536,51 \mathrm{ppm}$ & $3.406,25 \mathrm{ppm}$ & $9,99 \%$ \\
\hline
\end{tabular}

Ket: $*$ = Nilai konsentrasi dengan aktivitas terbaik 
Berdasarkan hasil penelitian diketahui bahwa ekstrak daun Lantana camara dari Famili Verbenacea mempunyai nilai $\mathrm{LC}_{50}$ paling besar yaitu 21,65 ppm. Uji toksisitas dengan metode BSLT ini memiliki spektrum aktifitas farmakologi yang luas, prosedurnya sederhana, cepat dan tidak membutuhkan biaya yang besar, serta hasilnya yang dapat dipercaya. (Frengky, 2014). BSLT dimaksudkan untuk memaparkan adanya efek toksik dan menilai batas keamanan dalam kaitannya dengan penggunaan suatu senyawa.

Hasil uji larvasida terhadap Culex fatigans tidak menunjukkan hasil yang memuaskan pada seluruh ekstrak yang diuji, tercatat bahwa konsentrasi terendah terdapat pada ekstrak Duranta erecta $L$. dari Famili Verbenacea dengan nilai LC $_{95}$ sebesar 1.717 ppm. Pengukuran toksisitas dapat ditentukan secara kuantitatif yang menyatakan tingkat keamanan dan tingkat berbahaya zat tersebut. Apabila harga LC50 $<1000 \mu \mathrm{g} / \mathrm{mL}$ maka ekstrak tersebut dapat dikatakan toksik. (Cassaret dan Doull's, 1975). Komponen yang bersifat larvasida biasanya memiliki aktivitas membunuh larva yaitu membunuh serangga belum dewasa dengan aktivitas sebagai racun perut, kontak atau pernafasan. (Sudarmo, 1989).

Hasil uji antimakan terhadap Tenebrio molitor cukup baik ditunjukkan pada ekstrak batang Euphorbia mili dari Famili Euphorbiaceae sebesar 2,707 \%. Gambar hasil bioaktifitas antimakan pada daun sawi (Brassica parachinensis) dapat dilihat pada gambar 1. Beberapa penelitian tentang bioaktivitas latex spesies Euphorbia milii menunjukkan aktivitas sebagai larvasida terhadap Schistosoma mansoni dan aktivitas anti hama moluscasidal terhadap B. glabrata B. tenagophila, B. pfeifferi, B.straminea dan Bulinus SPP. (Schall, 2010) (Lima MG, 2010).

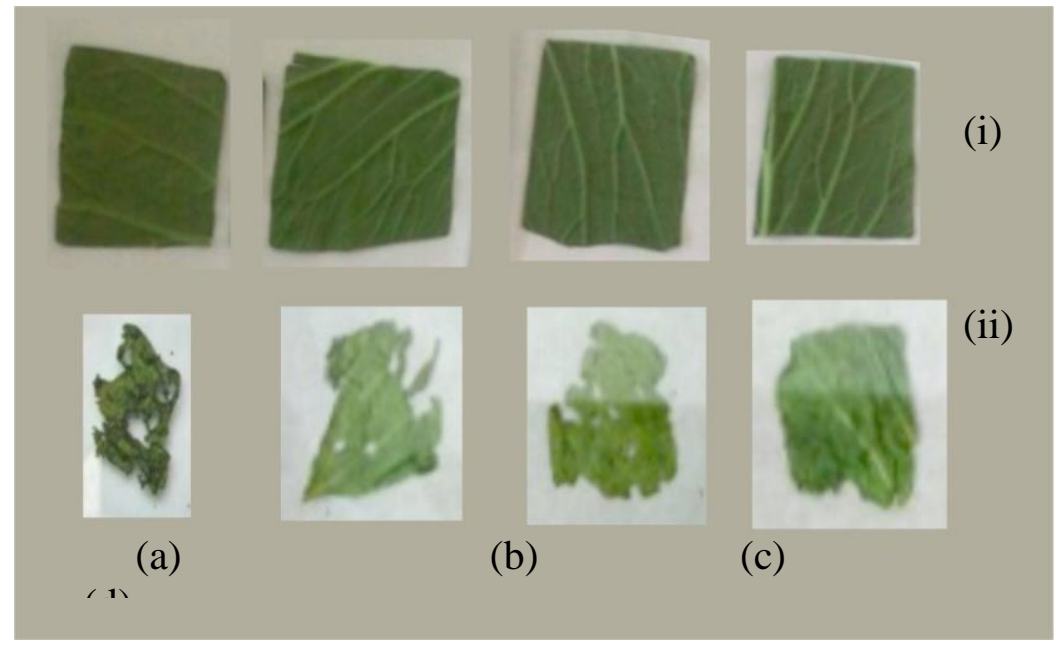

Gambar 1. Hasil bioaktivitas antimakan larva Tenebrio molitor pada daun sawi (Brassica parachinensis) (a) kontrol, (b) ekstrak 1\%, (c) ekstrak 2\%, (d) ekstrak 3\%, sebelum inkubasi, (ii) sesudah inkubasi.

Komponen bioaktif antimakan dapat mewakili suatu pendekatan lain dalam hal perlindungan tumbuhan. Komponen ini bersifat tidak membunuh, mengusir atau menjerat hama, akan tetapi bersifat menghambat makan (antimakan) saja. Zat tersebut menghambat makan secara sementara maupun permanen, tergantung pada potensi zat tersebut. (Gani, 2012). 


\section{KESIMPULAN}

Bioaktivitas $\mathrm{LC}_{50}$ metode BSLT terhadap larva Artemia Salina Leach paling baik terdapat pada ekstrak metanol batang Tinospora crispa sebesar 21,65 ppm; bioaktivitas larvasida terhadap larva Culex fatigans $\mathrm{LC}_{95}$ dari seluruh ekstrak tumbuhan tidak diperoleh hasil yang memuaskan; bioaktivitas antimakan terhadap Tenebrio malitor $\mathrm{IC}_{95}$ paling baik terdapat pada ekstrak metanol batang Euphorbia milli sebesar 2,707 \%.

\section{DAFTAR PUSTAKA}

1. Frengky, Ratlizawati dan Desi Pertiwi. 2014. Uji Toksisitas Ekstrak Etanol Sarang Semut Lokal Aceh dengan Metode BSLT terhadap Larva Udang Artemia salina. Jurnal Medika Veterinaria Vol. 8 No. 1

2. Gani, Abdul., dkk. 2012. Identifikasi Senyawa Bioaktif Sampel Organik Perkutan. Jurnal Bumi Lestari Vol 12 No.1.

3. Ghulam dastagir dan Farrukh hussain. 2013. Sarhad j. Agric., phytotoxic and insecticidal activity of plants of Famili zygophyllaceae and euphorbiaceae. University of peshawar, peshawar - pakistan. Vol.29, no.1.

4. Kannaathsan K, Senthilkumar A, dkk. V. 2007. Differential larvicidal efficacy of four species of Vitex against Culex quinquefasciatus larvae. Parasitol Res; Springer-Verlag; 101: 1721-3.

5. Karunamoorthi K, Ramanujam S, dkk. 2008. Evaluation of leaf extracts of Vitex negundo L. (Famili: Verbenaceae) against larvae of Culex tritaeniorhynchus and repellent activity on adult vector mosquitoes. Parasitol Res; Springer-Verlag 103: 545-50.

6. Lima MG, dkk. 2010. Carbohydrate metabolism in Biomphalaria glabrata infected with Schistosoma mansoni and exposed to latex from Euphorbia splendens var. Hislopii during its degradation. In: Int. Symposium Schistosomiasis, Rio de Janeiro. P 12.

7. L. J. Casarett and J. Doull. 1975. Toxicology. MacMillan : New York

8. Mariadhas Valan Arasu, dkk. 2013. Antimakan, larvicidal and growth inhibitory bioactivities of novel polyketide metabolite isolated from Streptomyces sp. AP-123 against Helicoverpa armigera and Spodoptera litura, BMC Microbiology, BioMed Central Ltd. 13:105

9. Sudarmo, S. 1988. Pestisida Untuk Tumbuhan Edisi II. Kanisius: Yogyakarta

10. Schall, V.T., dkk. 1992. Evaluation of temporal, seasonal and geographic stability of the molluscicidal property of Euphorbia splendens latex. Rev. Inst. Med. Trop. São Paulo, 34: 183-191. 